\title{
Imagining a Future in PreK: How Professional Identity Shapes Notions of Early Mathematics
}

\author{
ELIZABETH Graue \\ University of Wisconsin, Madison
}

ANNE KARABON

University of Wisconsin, Madison

KATHERINE KRESIN DELANEY

University of Michigan

\author{
KRISTIN WHYTE \\ University of Wisconsin, Madison \\ JIWON KIM \\ University of Wisconsin, Madison \\ ANita WAger \\ University of Wisconsin, Madison
}

This article describes how early childhood teachers engaged in a public preK professional development program. We examine how developing teacher identities mediated engagement with the discourses of developmentally appropriate practice, early mathematics, and funds of knowledge and how they connected present practice to an imagined future. We found that helping them to connect practice experience and new mathematical content knowledge through play allowed them to envision a meaningful place for math with young children. [teacher identity, early childhood, mathematics, funds of knowledge, identity in practice]

Early childhood (EC) education is a hybrid space that spans multiple contexts, relies on diverse disciplines, and is populated by varied stakeholders. It includes policy and practice, caregivers and teachers, infants and eight year olds, families and educators, and it plays out in homes, childcare centers, Head Start, and elementary schools. These varied spaces carry with them different institutional histories, systems of thought, practices, and roles (Bloch 1987). Though loosely bound together by an interest in young children, the divergent needs and resources available to support its work fray the EC community's connections.

The multiple faces of early childhood come together in sharp relief in the context of a relatively new policy option for children and families in the United States: public prekindergarten (preK). Based on 50 years of research on the critical nature of the preschool years for children's growth and development (Camilli et al. 2010; Gilliam and Zigler 2001), a growing number of states have invested in publicly funded programs for three and four year olds (Barnett et al. 2012). PreK programs represent the intersection of many EC practices-a mash up of preschool and K-12 education, spanning public and private contexts, sometimes targeted and other times universal, addressing kindergarten readiness through a focus on literacy and math, and/or social and emotional development (Zigler et al. 2011). These programs are often implemented by the state through local school districts, bringing together state education policy with elementary school bureaucracy in the context of preK sensibility.

Anthropology E Education Quarterly, Vol. 46, Issue 1, pp. 37-54, ISSN 0161-7761, online ISSN 1548-1492. (C) 2015 by the American Anthropological Association. All rights reserved.

DOI:10.1111/aeq.12086 
Despite the growing popularity of public preK, there is little research on its culturesspecifically, we know little about how diverse EC groups come together and translate cultural and professional practices or how EC identities form across boundaries of practice. This gap in our knowledge is important given President Obama's proposal to expand access to high quality preschool programs for all families in the United States (Matthews 2013). This influx of resources will require more collaboration across EC contexts, connecting public and private, and preschool and elementary programs to serve young children. The potential introduction of universal preK is also an opportunity to study the factors that shape the formation of EC identities and practices.

These issues were highlighted when we implemented and studied a professional development program designed to support culturally and developmentally responsive early mathematics instruction. The National Science Foundation (NSF)-funded program asked teachers to reconceptualize their relationships with families by building on family funds of knowledge (Gonzalez et al. 2005) and was premised on the idea that early mathematics could be a powerful tool for taking up children's resources in the classroom.

All of this occurred in the context of district plans for a new public preK program in childcare and elementary sites. The project shifted from abstract to concrete and back to abstract when the district delayed implementation of the program after we received notification that we had received the grant. We found ourselves in the position of having resources to provide professional development (PD) for a program that was a year away. This became an opportunity to see how teacher identities developed as they imagined how they might use PD content in a future preK program.

In this paper, we describe the experiences of a group of teachers working to connect their present practice to an imagined future, what we refer to as an imagined preK. We focus on how teachers' experiences with and beliefs about young children, families, and early mathematics shaped their conceptualization of the content provided in the PD. We examine how developing teacher identities (Holland et al. 1998; Nasir and Cooks 2009) mediated their engagement with three distinct discourses-developmentally appropriate practice, early mathematics, and funds of knowledge - and the experience provided by the PD.

\section{Literature Review}

The incredible diversity of EC settings for young children produces random rather than systemic programs of early care and education. As a result, services for young children can be found in education, health, and welfare organizations with little alignment or integration across sectors. These scattered services are the foundation for calls to create a preK-3 system that would facilitate communication and practice among the varied sites that serve young children (Guernsey and Mead 2010).

As they work with a wide array of contexts and children, the ways that EC teachers think about their practice vary as well (Blank 2010; Katz 1995). These differences are linked to divergent conceptions of what EC practices should be, influencing how teachers negotiate identities in practice.

For almost a century, ECE and schooling, as social institutions, have been about different things ... ECE historically saw a more active, "constructive" child learner than did school. It was more supportive of cooperative learning; treated domains of knowledge in a more integrated manner; and placed greater store in play as an important vehicle for learning and growth. ECE historically was primarily a psychosocial, rather than academic, institution, that is, attended more centrally to socioemotional (and physical) needs. [Halpern 2013:4]

Preschool teachers conceptualize curriculum through individual child needs and developmental patterns while elementary educators use disciplinary content as a source for 
practice (Hatch 2010; Stipek and Byler 1997). Recently, the standards movement has widened the gap between these two groups. Benchmarks and standards are critical elements in elementary practice (Brown 2008; Goldstein 2007) and less so in preschool contexts (Hatch 2002; Bredekamp 2009). These differences shape how teachers approach their practice and influence young children's opportunities.

A critical issue is the role that teachers envision for themselves in preK classrooms. Illustrating Piagetian roots, many EC teachers see themselves as facilitators who set up the environment and then stand back as children construct a rich educational experience (Lee 2006). While more socially oriented views of learning suggest an active, scaffolding role for the teacher, EC educators are stubbornly reticent, particularly when it comes to instructional engagement in play.

To further complicate these distinctions, teachers of young children are often uncomfortable with content-specific teaching (Hatch 2010). Accustomed to integrated notions of teaching that take up children's interests rather than isolated skills, a content focus is a challenge (Lee and Ginsburg 2009). Though literacy focused teaching practices are increasingly embraced by early educators, mathematics has been a shadowy figure in the preK curriculum (NRC 2009). Despite being a natural part of children's everyday activity (Ginsburg 2006), particularly play (Seo and Ginsburg 2004), mathematics is not typically seen as a natural context for EC teaching at home (Tudge and Doucet 2004) or at school (NCTM 2000).

In a context where mathematics is infrequently viewed as a natural part of the EC classroom, scholars have begun to examine how mathematics learning can be supported in EC settings (Lee and Ginsburg 2009). Young children can learn mathematics when adults mathematize children's activities without disrupting play (Eisenhauer and Feikes 2009; van Oers 2010); and the play-supported ideas may later be shared among children in informal settings (Klibanoff et al. 2006; Thomas et al. 2011). Building on home knowledge has been a productive source of mathematics teaching and learning with older students (Civil and Kahn 2001) and would seem to be a natural approach with young children (Abreu 1995).

All of these ideas were catalysts as we designed a research project to support teacher thinking about developmentally and culturally responsive mathematics in a local public preK program. Recognizing that we would be exploring how teachers thought about themselves, their students, families, and curriculum, we began to frame our work in terms of identity (Cohen 2010; Zembylas 2005).

\section{Notions of Identity and Community}

[I]dentities are lived in and through activity and so must be conceptualized as they develop in social practice. . . Identities are key means through which people care about and care for what is going on around them. They are important bases from which people create new activities, new worlds, and new ways of being. [Holland et al. 1998:5]

From a practice perspective on identity, individuals sharing common interests interact to form connections that help to define themselves and others (Holland et al. 1998). The recursive nature of these experiences, from practice to definition and back to practice, cannot be ignored. Multiply determined through history and ideology, this practice perspective is enacted locally in both physical and imaginary contexts. Through exploration of spaces where individuals imagine themselves and others, we can examine how individuals brought with them: 
socially and culturally constructed realm[s] of interpretation in which particular characters and actors are recognized, significance is assigned to certain acts, and particular outcomes are valued over others. Each is a simplified world populated by a set of agents . . .who engage in a limited range of meaningful acts or changes of state . . as moved by a specific set of forces. [Holland et al 1998:52]

A social perspective on identities was a jumping off point to the notion of imagined communities (Anderson 2006, cited in Holland et al. 1998), which are as real as physical communities and affect learning through individual affiliations. The notion of an imagined community was helpful as we worked to understand how educators variably took up the ideas that the professional development had to offer. These imagined communities became one of the contexts for teacher learning.

We were also informed by Nasir and Cooks (2009) who distinguish between learningthe use of artifacts in solving problems, making meaning, and interaction - and identitythe sense of the self in practice. Like Nasir and Cooks, we were interested in "how such local connections between self and activity are fostered through interactions whose purpose is teaching and learning" (2009:44). Particularly helpful is Nasir and Cooks' use of identity resources as tools to understand learning. We examine how material, relational, and ideational resources available in the PD support the developing identity of potential preK teachers.

\section{Methods}

\section{The Prekindergarten Professional Development (preKPD) Project: A Teaching-Research Hybrid}

When a local school district embarked on the implementation of a state-funded public preK program, Beth Graue, an EC educator, and Anita Wager, a math educator, designed a professional development program for preK teachers. A number of issues prompted this effort. The play-based preK program was designed for childcare and elementary sites. The district anticipated that a number of current kindergarten teachers would move to preK and that it would need to hire new teachers. This boundary crossing effort meant that the cultures of elementary and preschool would intersect and in some cases become interwoven. Second, like their colleagues across the United States, the demographic changes in society have increased the disparity in the cultural backgrounds of EC teachers and their students (Sleeter 2001). For this reason, we felt that it was vital to build the capacity for teaching that attends to both the developmental and cultural resources children bring to school. Third, we saw an opening for play-based curriculum development around early mathematics because mathematics has been conceptualized as more predictive of later achievement than early literacy (Duncan et al. 2007; Romano et al. 2010). With these targets, we designed a PD program for practicing teachers focused on developmentally and culturally responsive mathematics teaching based on funds of knowledge (FoK).

The concept of funds of knowledge, originally suggested by applied anthropologists Carlos Velez-Ibanez and James Greenberg (1992), is defined as "historically accumulated bodies of knowledge and skills essential for household functioning and well-being" (Gonzalez et al. 2005). Norma Gonzalez and colleagues applied this perspective in education settings, focusing on working class Latino/as and their school experiences along the U.S.-Mexican border. Researchers using FoK frameworks worked to recognize the rich knowledge of low-income and minority families, challenging the prevalent deficit model concerning these households (Moll et al. 1992).

\section{Participants}

We recruited teachers with EC certification, beginning with $18^{1}$ participants, almost evenly divided between community and school sites. Our participants included preschool 
teachers in non- and for-profit settings, center administrators, kindergarten and first grade teachers, and one district special education resource person.

\section{Description of PD Program}

The project was designed to deepen the ways that teachers knew their students. On the one hand, we focused on culture by introducing teachers to the idea of recognizing and utilizing children's FoK. We also included a cognitive component by building teacher knowledge of children's mathematical development by extending cognitively guided instruction (CGI) (Carpenter et al 1999). We hoped that teachers would link the specific cultural practices exemplified by FoK with generalized cognitive knowledge of children's mathematical understanding to respond in authentic ways to children's skills and experiences. Our goal was that the power of FoK and CGI would create a synergy that enhanced teaching and learning.

Participants engaged in a four course sequence funded by NSF, the school district, and the University of Wisconsin Madison. Graue and Wager co-taught courses that wove together EC theory, early mathematics, and funds of knowledge through readings, activities, and out-of-school projects. In line with the original FoK work (Gonzalez et al. 2005), a key element was the creation of a space for teachers to reflect on their experiences. A hybrid of traditional PD and graduate coursework, the program met weekly for 2.5 hours. Teachers explored readings, participated in a mix of whole and small group activities, and wrote reflections that connected to their practice.

To help them think more deeply about FoK, we asked teachers to work with a focal child that was different from themselves on two dimensions (race, class, language, or gender). They designed and conducted home visits and translated what they found out about their focal child into educational activities. One of the complications of this focal child project was that the delayed start of preK meant many of the teachers were not working with four year olds at the time of the PD coursework. To even out the playing field between the preschool and elementary teachers, we asked that they work with a child who was not in their class.

We adapted the FoK home visit to help the teachers explore children's cultural resources. Situating teachers as learners about family practices, we asked them to enter students' homes as ethnographers. Our participants designed instructional activities that incorporated practices and ideas that represented family competence and knowledge familiar to the students (Moll et al. 1992).

We complicated this anthropological approach with the addition of our focus on mathematics, supporting our participants' conceptualization of how math would be a key part of the home visit conversation. The teachers began by developing interview questions focused on family life, including information about household members, occupations, kinship, location of birth, and daily household practices. This information served as a context for understanding family math practices embedded deeply in other activities (Abreu 1995; Baker et al 2003).

Across the courses, we audiotaped group discussions from 25 class sessions, collected artifacts produced in activities and assignments, and interviewed the 17 teachers multiple times. These data serve as a foundation for our analysis. We began the analysis for this paper by reading through the data with group members approaching the data in two ways: each of us took at least one month of data and one teacher, and we read through those data carefully, coding segments that exemplified the core elements of the project: EC education, early mathematics, and FoK. Within these codes we developed subcodes as the analysis developed. For this particular paper, we organized our analysis around the themes: 
- Constructing EC teacher identities

$\bigcirc$ Engaging with the discourses of developmentally appropriate practice, early mathematics, and funds of knowledge

We read and coded recursively, linking joint understanding through a project journal and meeting weekly to discuss developing themes. Writing was an important aspect of the analysis, which we did collaboratively among team members. A key element of our work was simplification of the theoretical frameworks employed to facilitate our analysis. What was initially a crazy quilt of tools became more parsimonious through feedback from journal reviewers.

\section{Imagining a Future in PreK}

\section{Imagining EC Contexts}

The implementation of preK in this district represented a hybrid form of EC education. Through a mixed model approach, the district partnered with community childcare centers and Head Start to locate preK classes in both schools and community. Representing more than a decade of negotiation, the public-private partnership brought together two professional groups with vastly different approaches to education. The district, a large bureaucratic organization, was increasingly driven by standards and benchmarks. This evolution was one reason that a number of kindergarten teachers were interested in moving to preK; they no longer felt that kindergarten was appropriate for five year olds. The community sites were small, private organizations or Head Starts committed to "developmentally appropriate practice" (teaching grounded in knowledge of child development and attuned to a child's individual and cultural background). There was an undercurrent of concern in the preK negotiations that this partnership would result in drill and kill programming that was antithetical to the EC community. In this context, our teachers were asked to conceptualize a way of teaching preK that required different tools than many of them had in their professional toolkit or to repurpose well-worn tools in new ways.

The teachers approached preK curriculum from three distinct approaches. The first group of teachers approached teaching through traditional notions of EC development. Kathryn $^{2}(\mathrm{PK})$, Allison (PK), Rose (PK), and Amanda (PK) believed that everything they needed to build curriculum existed within their classrooms. Hannah (PK) and Dee (PK) were also preschool teachers practicing from this developmental perspective but newer to the field, with less than five years experience teaching. Their voices were quieter in conversations about the source of the curriculum. The developmentalists in the group saw teaching as based on professional knowledge of development, materials and pedagogy, and their observations of their students. When asked to describe her philosophy of teaching, Allison replied:

Just setting up the environment and really having it be inviting and engaging. We spend an awful lot of time setting up the classroom. To a certain extent once the kids arrive then most of my work's done. I mean not completely but then they're engaging and they're making choices of what they want to do and, so I think, it's you know it's hands-on it's engaging. You know so it's relevant and important to the child. [Allison, PK, fall interview]

Looking outside of this developmental knowledge was interesting for these teachers but not important to the design and implementation of developmentally appropriate curriculum.

Others organized their instruction and goals for students according to grade level expectations. Lynn (1), Lyla (K/1), Clover (K), Marie (K), and Ruby (Special Education) 
were veterans from elementary settings highly focused on district mandates and learning objectives. Working in contexts marked by growing standardization in teaching they built practice from benchmarks to children.

Lyla (K/1): That's why I like the district, they give you this binder, and it has the math assessments. And so it really guides you, it gives you all of that, how to ask those questions, like how to start from two and count on. So I'm wondering if they're going to do that for the preK classrooms, if they're going to give us like a math binder. Or are you going to come up with your own questions? Dee (PK): Because it's hard to come up with questions

Lyla: Especially if you don't know what you're looking for.

[Small group, 10/13/2010]

For these teachers, understandings of curriculum were anchored to a local context where children had to meet certain benchmarks and standards; the teacher's job was to get them there by the end of the year.

A third group believed that knowing the children in their classrooms was necessary but not sufficient to meet individual needs. These teachers found the notion of FoK interesting and a potentially useful approach to strengthening the resources available for instruction.

I think you really want to make a connection with the family and that's so important. I think that families want to know-they want us to then establish a relationship, and part of a relationship is trust. And I think that that sometimes can be a difficult thing to do. If you're dealing across cultures, that can be a challenge. But, I think the more you can make a connection with the family, the more the teacher can, through time, across a great greater acquaintance with their funds of knowledge, and the more you're aware of what their fund of knowledge is, the more you can think about integrating those different approaches to math, and add as a foundation for additional math learning. [Anoka, PK, fall interview]

Penelope (PK), Harold (PK), Anoka (PK), Andie (K), and Fiona (K) repeatedly engaged in conversations about FoK and could see its value as a curriculum source. These teachers recognized the importance of developmental and standards-based teaching and were open to the expansion of resources made possible through FoK.

As they worked with children, four year olds' capacity came into focus and assumptions were disturbed as they found that experience, rather than development, limited learning. Anoka described how he initially thought a problem would be out of reach for a student but reconsidered when he saw how she responded to modeling:

She's four and she'll be five this year. She reads fluently and I didn't try the last one 'cause I knew that was ridiculous. Then I did some modeling with her with the cubes. And she just grasped it immediately. So I think in her case it's just a matter of never having access to that type of tool to solve that problem. [Anoka, PK, small group, 12/01/2010]

Anoka used a child's age to judge a task but then realized that he might be underestimating what she could do after he modeled solving the problem with props. His recognition that experience might have shaped her response is nicely linked to the conception of FoK.

In these descriptions, we see glimpses of identities in practice. At each stage of the PD program, the teachers worked to imagine enacting preK, with many teachers struggling to stage a program in their minds that might be a hybrid of preschool and elementary practices as well as a melding of home and school knowledge. Across these distinct perspectives on teaching, our participants struggled to imagine what four year olds could do.

\section{Imagining PreK Mathematics}

Harold (PK): Like maybe not even realizing she's counting. Is that really math? Maybe not realizing that it is math. 
Clover (K): Well thinking more broadly about mathematics away from the way we think of it as sort of a hierarchical set of skills. It's in places and communal situations where we might not readily recognize it so we have to learn how to see math in other places.

[Small group, 02/16/2011]

In the imagined space of preK, we asked the teachers to use the resources that children had at home in instructional design. Further, we asked them to consider the idea that mathematics was a fertile source for EC curriculum. This focus reflected our hunch that attention to early mathematics could be a productive leverage point for teachers. At the heart of this component of the PD was the question of what IS math for four year olds? How do we recognize math if it isn't in an explicit math activity or concretely written into a curriculum? When children make errors, is it math if it is left uncorrected? For our participants, determining what mathematics would look like in a preK context was predicated on their imagined views of preK curriculum and teaching.

As teachers wrestled with potential changes in their professional practice, they began to imagine what form mathematics might take in preK. A discussion about teacherdirected versus play-incorporated mathematics learning provides a window on their thinking:

Anoka (PK): Well, we could say like rote counting. That would be learning by rote. Is that a good thing or a bad-good practice or a bad practice in preK? Is there some value to it? Is there no value to it?

Lynn (Grade 1): Well, you do that a lot in kindergarten. Right, Clover? Rote counting. I mean that seems like-is that a good practice or a bad practice?

Clover (K): Well, you know, it depends if you can integrate it into what you're doing.

Lynn: Counting for a reason. If you make it purposeful.

Clover: Like the hot lunches and cold lunches? And who likes peaches and who doesn't.

Lynn: Counting the days of school we do. Because I mean they have to have practice counting.

[Whole group, 09/08/2010]

In this conversation teachers worked through connecting preK mathematics to a classroom routine, something they considered a meaningful activity. This is eminently sensible given our understanding of young children. But what is meaningful activity? Lynn and Clover (both elementary teachers) sought to embed math (in this case counting) in routines. ${ }^{3}$ In a different conversation, Shannon, (PK), imagined math in play, seeding dramatic play spaces with math-evoking materials:

It would be things like setting up a pizza parlor, and the child would be counting money, or if activities within that setting that would inspire-would bring in the math, in a very particular way. [Small group, 9/22/2010]

\section{Anoka connected math with other developmental domains:}

So in terms of relating it to other domains, we looked at mathematics, and a lot of movement activities can be incorporated into counting and mathematical activities. ... Lots of opportunities to learn how to count [in the daily routine] and have that reiterated so that children really learn how to get fluent in counting. And we have many other things we could use to reiterate these mathematical concepts in the context of physicality. [Anoka, PK, whole group, 10/27/2010]

Some teachers had much experience with content-focused PD in literacy and mathematics. In fact much of the local elementary PD in mathematics had focused on CGI, which the local school district embraced as a vehicle for teaching about numbers and operations in the primary grades. In contrast, others had experienced more diffuse PD that focused on creating experiences for their students rather than specific skills that they should be teaching. This was beginning to change as the district had recently broadened a 
set of workshops for preschool literacy to include math, so childcare providers were beginning to explore the role of early math in preschool settings.

This past PD and experience shaped the teachers' comfort and expectations for the types of math experiences they thought were reasonable for four year olds. Following a class session that identified a typology of word problems representing different mathematical concepts, we asked the teachers to try some problems with their focal children or their current students. Examples of age appropriate word problems might include "Jasmine has three balls. She finds one more. How many balls does Jasmine have altogether?" or "Enrique has four cookies. He wants to share them with Jack. How many cookies can each boy have?" The teachers met variable success using word problems depending on the age of their students:

I did some CGI problems in a small group in my kindergarten classroom. . .to me, it was pretty typical where some kids who are able to do it right away in their heads and some I needed to help model the problems. [Andie, K, small group, 12/01/2010]

Some of the teachers were skeptical about using CGI with four year olds. As the teachers continued to think about integrating the word problems into the preK curriculum, these concerns came to the fore. Ruby argued "Because I think that [some problems are] going to be difficult for most four year olds." Harold agreed, "Yeah, I think that would be really hard for them" (small group, 12/08/2010).

Allison was an elementary teacher before switching to teach preschool. She was very familiar with CGI but did not use it in her work with preschoolers because she did not think it made sense with younger children.

I taught first and second grade. And all we did was CGI stuff. And it just made me think how I don't really do story problem-type things like that with my younger kids. [Allison, preK, small group, 12/01/2011]

We began to see that a strong grasp of mathematical content was not enough to support teachers' incorporation of CGI in imagined preK contexts. If the teachers did not see how the content fit into their ideas about pedagogy, it was difficult for them to imagine why and how they would teach it. This point is nicely parallel to work that has found that students' mathematical identities require more than strong math abilities; it requires participation in authentic activities and a self image as a mathematician (Boaler 1999; Boaler and Greeno 2000, cited in Nasir and Cooks 2009).

While the focus on specific math content challenged many of the teachers, the idea of integrated and authentic mathematical experiences for young children was very appealing. ${ }^{4}$ They began to imagine what was possible with four year olds. This switched the focus back to creating experiences for young children rather than directly teaching young children certain skills or problem types, which energized the preschool teachers. Amanda described using a balance as a concrete tool for teaching about equality by providing a physical context for practice:

I also took my math area, and I took some of the same rocks and stuff and put them in there with the balance scale. So they're doing math with it, but they're also getting the science and nature and discovery, and there's magnifying glasses there too, so I try to kind of tie in other areas of learning with the whole discovery thing. [Amanda, PK, small group, 05/04/2011]

The teachers considered the resources available that would support mathematic experiences in their classrooms.

Considering the above examples, we wondered what made mathematics meaningful in preK. Meaning is multilayered and context specific, which brings a number of issues into 
focus. For example, do we count hot lunches in kindergarten because students need to know the number of hot and cold lunches to go about their kindergarten lives? Probably not, unless they also work in the lunchroom. Or do we do it as an excuse to teach counting? For whom is this meaningful? How is it different from a dramatic play context where children use math in their play?

We came to the conclusion that activities are taken up differently, depending on a child's developmental status, culture, and perspective. Therefore we needed to be mindful that these activities might carry different meanings for each child. For some children, counting lunches is rational, involving matching each lunch with a number. For others it is rote counting with children reciting numbers rather than counting objects/people. The hope is that the practice in rote counting will serve as a foundation for learning to count. This analysis helped us to recognize that the meaningfulness is negotiated between teacher and student. This distinction about meaningful context was an enduring tension in the PD. It represented imagined preKs that were variably teacher directed or child centered.

\section{Imagining Funds of Knowledge through Home Visits}

To support the teachers' understanding of FoK, we asked them to do home visits with their focal child's family. Though interested in children's social and cultural resources, the teachers were skeptical about the implementation of a classic FoK approach (Moll et al. 1992). At the most basic level there was fear about venturing into homes, with questions about personal safety and the family's comfort. Harold described simultaneous excitement and concern as the time crept closer to visiting his focal child:

[A]s time went on I began to be more and more nervous. Not necessarily because I was worried about feeling uncomfortable or unsafe but because I was concerned that my focal child's mother did not want to meet. [Harold, PK, home visit reflection]

Regardless of previous experiences, the teachers viewed home visits as tools to teach families how to help their children learn outside of school. After Anoka's first home visit he worried about how to give the family ideas about what to do at home.

I've been thinking about what suggestions I would have for them. . .I was trying to think about ways that I might recommend things. I could recommend going to the library to get counting books. I mean that's something that hopefully is not going to be offensive. [Anoka, PK, home visit reflection]

In contrast to this well-honed role as expert, we asked teachers to inform their practice by seeing home visits as opportunities to learn from families. This ethnographic approach forced an identity shift, from teacher to learner. As teachers became more familiar with what it meant to enter a home as an ethnographer, they wondered how they would learn enough specifics about the mathematics practices in their students' homes.

There was a great deal of debate about how they were supposed to learn about a child's "funds." Reflecting on their own family math practices, teachers realized how often math could be unknowingly present. They were concerned that families wouldn't recognize many home mathematics practices and worried that if asked questions about math at home the families would talk about workbooks or direct teaching. Congruent with a FoK approach (Civil and Kahn 2001), the teachers wanted to learn about the math embedded in family routines, activities, and interests. This brought up an interesting issue: How could you expect someone to answer a question about something that they are unaware they are doing? This prompted the teachers to imagine integrating their focal children's funds of knowledge into their practice. 
In the foundational work on funds of knowledge (Moll et al. 1992), teachers did ethnographic home visits with a subset of their students' families. Beyond the simple issue of time to do home visits for all families, FoK discussions among the participants frequently circled back to a question of equity. It seemed that if you did home visits for a few, you were spreading a potential resource unequally. Kathryn focused on this repeatedly, worrying that doing home visits with only one or two children would be upsetting for the other students and that not including the funds of all the children she worked with would lead to inequitable practices.

I understand. . . funds of knowledge is to be a better observer. . .But I thought also the reason for doing this is to make your classroom practices better. But I don't see if you're only doing three students. . .then you haven't gathered that knowledge from the other students. . this seems like it's unequal. . .So then do you base your classroom practices on what you've learned from these three families? I mean how does that do any good? [Kathryn, PK, whole group, 02/16/2011]

We were puzzled why some teachers would frame a practice that originated out of concern for equity and diversity as potentially unfair. When we looked carefully at who held this concern, we could link it to the preschool teachers who we identified as traditional developmentalists; they had in their classroom all the resources they needed to build curriculum. They framed FoK informed home visits as a resource that they would give rather than an information source that provided relationships and information that would inform their practice. In their imagined world of preK, home visits with a small number of children could result in perceived favoritism. As the teachers worked through barriers of time and equity, they found value in the funds of knowledge approach. Imagining the preK classroom, teachers developed ways to incorporate what they might learn from home visits into their future curriculum. Rather than layering math at school on top of children's home resources and experiences, we challenged the teachers to think about integrating the two. How could meaningful math activities be incorporated into play that honors and reflects the child's experiences outside of the classroom?

\section{Imagining Connections among Play, Math, and FoK}

An imagined sense of preK mathematics evolved over several months. As the year progressed, many of the teachers developed a vision of preK math knowledge but also how to provide these experiences in a rich and authentic way. Linking an emerging understanding of FoK, a group brainstormed how to mathematize in the classroom a family's experience camping. They knew that the child's experiences should be reflected in their math activities. As they worked to connect mathematical ideas with camping, their definition of content became narrower, almost grafted on to the theme of camping. Only Marie tried to broaden what math might look like in a camping context, but the group did not take up her ideas. Instead they focused on counting camping stuff:

Penelope (PK): What are we going to do there though? Like after, if you camp how is it related to a school math practice?

Fiona $(\mathrm{K})$ : You could count things in nature or maybe sticks or maybe a rock collection

Marie (librarian): Well if you are going to be gone-if you're sleeping for how many days, how much food you would need? You have a compass or you know you'd have?

Allison (PK): You could count marshmallows.

Fiona: Yea count marshmallows, count smores.

[Small group, 11/23/10]

Curriculum construction designed to reflect children's experience was a new task for many teachers. In this discussion they worked to bring together the discourses of the PD, 
but the depth of experience was limited. We wondered if it would have reflected more complex conceptions of mathematics, play, and FoK if they had been working with a focal child in their classroom.

In some cases a growing confidence and knowledge came out when teachers were discussing the assessment of math skills in their future preK students. Allison focused on how a teacher can recognize math skills in play rather than by pulling kids for one-on-one encounters to assess their skills:

Allison (PK): On the table are blocks. And they are stacking them. And they just start counting and then start comparing whose is taller. And so then it just sort of comes out of that social play. . It seems like if I design it and say, "here, do it" then I've lost the play part of it.

Ruby (district resource person): Right. The spontaneity of it. Counting and social skills.

[Small group, 10/27/2010]

Allison is describing the tightrope that preschool teachers walk as they work to support children's learning. Teaching in play was a powerful but challenging idea for the teachers, with the sense that a wrong step would result in losing the teachable moment. As the teachers grew their sense of how to implement math in the curriculum, as well as assess their future preK students' math knowledge and understandings, they began to see math everywhere.

At the beginning of the year, Clover's conversations about teaching math focused on basic counting. The conversations seemed limited to very simple tasks and isolated math experiences: "Counting the number of cars in each group. . The kids can also think of their own ways to sort" (Clover, K, small group, 10/27/2010). By the end of the year Clover's discussions about math became contextualized and much richer as she described the way math was integrated into her classroom. In her descriptions, she relates the CGI content to her knowledge of EC pedagogy:

[W]e just did a big pet store, and we did CGI problems with the pet store, and we sorted and counted the animals. . we wrote how to care for our pets, something that they could give out to the people who buy the pets. . .we discussed the jobs, and charts of what jobs they wanted people to have. We talked about the money involved, like what do workers get; and where does the money come from. [Clover, K, small group, 05/18/2011]

These conversations illustrate a critical attribute of the teacher's role in the imaged preK context. The teacher's role in preK mathematics is a responsive one that sometimes requires specific instruction and other times a more indirect scaffolding of child experience. For example, many participants commented on observing math during play:

She was in the dress up area with a Halloween costume on having a tea party. And she was counting her friends in the room, without any prompts. . .I was just observing her. Then another friend came over and she started counting again. And she had a little plastic pie. And it was a whole pie. And then she had a piece. And I asked her, "Well, how many pies do you have?" And she starts counting the lines on the pie [the slices on the top to aerate the pie while cooking]. "I have six." I'm like, "You have six. How do you have six?" "Well, see these lines. That's six." [Hannah, PK, small group, 10/27/2010]

Near the end of the PD, teachers were naturally making connections between mathematics (not just numerals and counting) and play, how to incorporate and observe mathematics in different learning centers in the classroom. Working one on one with her focal child, Allison was energized by the mathematical thinking she observed in her focal child:

It's really neat building with her. . there was a red pattern block, and she got pretty used to the names, hexagons, whatever. When she got stuck, I'd say "well let's look at this and how does this fit, which side, or what shape or like that. .." [Allison, PK, small group, 05/11/2011] 
Imagining what mathematics would look like in preK created a space for the participants to grapple with their beliefs about child development and their previous experiences as educators. While this approach felt uncomfortable at first, over the course of the PD almost all of the teachers had come around to the idea that early mathematics could be incorporated into play, routines, and intentional teaching in authentic ways. Amanda (PK) reflected on conversations with children about math they identify in home routines and play:

Another boy told the class about counting chicken nuggets at the dinning room table. He gets to take five chicken nuggets and his sister only gets two. You see he is five and she is only two. "She says that she is five," he tells me! [My focal child's] parents count when he is to do a task to see how quickly he can get it done. (Twenty seconds to wash his hands) "That's how long it takes to get rid of the germs." "We play. ...ONE, TWO, THREE JUMP off my bed at night!" It seems as though no matter whether parents think their children is engaged in math and counting or not, their child is picking up all kinds of math related concepts in the things that they do at home or with their family. [Home visit reflection]

Children's FoK was coming into focus for Amanda; the next step would be designing instruction with that knowledge in mind.

We pushed teachers to decenter their practice-in some cases by inches, in others by miles. By valuing the resources in children's homes, we asked teachers to give up some of the authority as the knowers in their classroom and to think about what they could learn from families. We pushed that even further by asking them to incorporate their focal child's FoK into their teaching. As they expanded their notions of appropriate curriculum content to include mathematics, they explored the imagined parameters for the learning and developmental capacities of four year olds. The key for them was doing so in a manner that was developmentally responsive to their conception of a typical four year old but more importantly their focal child. As we worked to make meaning of this process, we returned to the notion of identity in practice and identity resources. In the final section of the paper, we use these tools to understand our participants' experiences.

\section{Identity in Role/Identity in Practice}

One of the main goals of our project was to gather EC educators to conceptualize early mathematics in a preK classroom based on the resources they bring from home. Through participation in a community of practice, we hoped that teachers with similar interests but different identities would develop a shared commitment to play-based pedagogy that would serve as a bridge between home and school. Whether or not communities emerge, however, depends on the development of mutually supportive knowledge that engages learning. The basis for this shared knowledge largely develops from the participants' identities in practice and how these identities are leveraged into making connections that lead to communities of practice.

The PD was launched in a context of a delayed preK program, a hopeful but skeptical partnership between the local school district and community childcare centers. The challenge of bringing together professionals from disparate segments of the EC community and concern that the new program would be colonized as a watered down version of kindergarten were threaded throughout this complex experience.

What was learned as a result? We found Nasir and Cook's (2009) identity resources particularly useful in understanding the connection between identity and learning. If material resources influence the "ways the physical environment, its organization, and the artifacts in it support one's sense of connection to the practice" (2009:47), then they were a strong force in the creation of identity and learning. The opportunity provided by the grant created a space for the development of a community of practice where none had existed before. 
Working in an imagined teaching context due to the delay of preK, the connections that teachers could make to the PD program were limited by material resources that constrained connections to practice. As a result, imagining preK practice was somewhat like operating in a vacuum. The ideas presented in the PD had limited capacity to leverage change because they were interpreted through the lens of the present, non-preK practice and material resources. Even our attempt to connect them with four year olds through the focal child assignment had constrained utility. Separated from their practice, the teachers did not have a clear line of sight to link their learning from accessing funds of knowledge with ongoing learning in a classroom. We are not arguing that the assignment was useless, it just tells us that authentic pedagogical connections are very important if we hope to leverage change.

The practice experiences of the participants posed another complexity in our project. The project purposefully pulled together educators from a variety of contexts, with preschool teachers from for- and nonprofit centers, EC specialists, a librarian, and kindergarten and first grade teachers. One of our goals was to develop a community of practice that would serve to support the changes the program was designed to foster. Relational resources are the relationships that provide connections or barriers to learning (Nasir and Cooks 2009). Did relational resources support learning in this context? By gathering diverse early educators to discuss pedagogy in preK, we hoped that relational resources would provide social connections for learning. In many cases, a powerful synergy was created as the teachers shared ideas and practices. But this diversity was also a constraint. The group had difficulty gelling because they came from diverse teaching contexts with varied practices and beliefs about teaching and children. Their connection was something that did not exist yet. At the level of the teacher and the focal child, the relational resources were limited by the fact that the focal child was located outside the teachers' classroom so the implications for making deeper relationships with families had limited traction. However, even given these constraints, talking about FoK seemed to plant seeds for many of the teachers, who began to question the ways that they oriented to families and the resources they had for educating their children.

How teachers thought about good practice and their role in the world of EC education is what Nasir and Cooks (2009) call ideational resources. This was the element that may have had the most profound effect on how the PD program played out and the learning produced. All the teachers in the program were certified EC educators who were interested in the preK program. This set of ideational resources was somewhat elastic, bringing them together initially, subtly fracturing the group into subgroups, but ultimately providing a context for shared commitments to practice. Beyond being EC teachers, their broader professional identities were dependent on their working context, histories, and their beliefs about high-quality preK and the potentials made possible by the intentional teaching of early math.

In the PD, we were working to shift deeply rooted ideational resources. We asked that the teachers share authority with families for the resources that were valuable for supporting learning. We asked them to think about mathematics as a fertile context for learning with four year olds. In addition, we asked teachers to imagine teaching with a combination of more explicit and more responsive strategies. All of these were related to their particular senses of the role of the teacher and the needs of young children. This complex set of new ideational resources was a heavy lift in the context of an imaginary preK program and a group with splintered allegiances.

This is not to say that we made no progress in this effort. Initially we identified only micro changes to the teachers' thinking, but this analytic opportunity has shown that our work permeated the substantive boundaries that identity resources can place in relation to change. Our discussions show that the teachers broadened their conceptions of EC curriculum to include mathematics and were (1) increasingly able to identify potential math- 
ematical content within typical activities and (2) able to begin to make connections between the resources children brought to school from home and the potential of a mathematically rich EC curriculum. A key to this growth was their recognition that conceptually rich play was a fertile source of mathematics learning. Rich play-based mathematics required meaningful contexts for learning and a responsive teacher who knew when to be more or less direct in instruction. Their identity resources mediated the teachers' enactment of early mathematics; this parallels our hope that teachers would take into account the funds of knowledge their children bring to school. The learning that could take place within the constrained context of the teacher community was related to the identities available in the context of the PD. In turn, those identities were related to the implementation context of the PD.

Now in the third year of our project, we have the benefit of having two additional cohorts, two years of interaction with the cohort one and two, and time and experience to boost our identity resources. Our PD curriculum is still designed to decenter teacher practice so that more children have access to high quality early mathematics in rich EC contexts informed by children's funds of knowledge. The quality of the third year is a result of two years' learning and the opportunity to engage in rich interactions with a skilled group of teachers. We have benefited greatly from reflecting on our own practice in supporting their journey towards teaching intentional mathematics and developmentally responsive curriculum in preK classrooms. We are grateful for the opportunity to learn from them.

What implications might be drawn from our first year? The first is that professional change, whether it is related to practice, knowledge, or interaction, is mediated by the context. We came into the PD hoping that we could create a learning community that would support teachers interested in changing their practice in the context of preK. The success of that work was both facilitated and constrained by the participants' identities in practice. For anyone familiar with either pre-service or in-service teacher education, this would not be a surprise. But our participants reminded us that they bring to their practice histories, beliefs, and abilities that shape how they take up the experiences that we provide in PD. We have come to think about this as essentially a teachers' professional FoK. In imagining preK, our participants naturally drew from their previous experiences and contexts of schooling (Moloney 2010; Hedges 2011). Recognizing and building on these accumulated ways of knowing is vital when providing PD for an imagined future.

The second is that the dual foci of early mathematics and FoK are most deeply understood in relation to their context in the third aspect of the PD: developmentally responsive education. All of the participants were nominally early educators, representing an array of early education contexts. A shared notion of the needs of young children was developed in this jumbled context, one that reflected the delayed beginning of the preK program, the press of the accountability movement, and the different values of the preK and K-3 systems. The meanings of FoK and early mathematics developed in this context, negotiated over the nine months of the program among the teachers and researchers. More than anything, we realize that these three elements, which we struggled to bring together, are now almost impossible to pull apart. One take home message of this project is that integrating bodies of knowledge in education activities is a process, one that occurs from conceptualization, pedagogy, and analysis.

Elizabeth Graue is Sorenson Professor of Early Childhood Education and chair of the Department of Curriculum \& Instruction at the University of Wisconsin Madison (graue@ education.wisc.edu). 
Anne Karabon (karabon_a@yahoo.com), Kristin Whyte (kristinwhyte@gmail.com), and Jiwon Kim (Jikim436@wisc.edu) are graduate students in early childhood education at the University of Wisconsin Madison. Kate Kresin Delaney (delaneyk@umich.edu) is a postdoctoral researcher at the University of Michigan.

Anita Wager is assistant professor of Mathematics Education at the University of Wisconsin Madison (awager@wisc.edu).

\section{Notes}

Acknowledgments. The writing of this paper was supported in part by a grant from the National Science Foundation (144PRJ38LF). The opinions expressed in this paper do not necessarily reflect the position, policy, or endorsement of the National Science Foundation. We are particularly grateful to Tom Carpenter for his unique role in this project. Many of the lessons he taught we only came to understand this year.

1. Over the course of the first semester, two participants dropped out due to personal conflicts.

2. The teachers chose their own pseudonyms.

3. The notion of rote counting connected to meaningful activity represents an interesting misunderstanding of the definition of rote counting. In this data segment the teachers conflate the idea of rote counting (saying the number words in a correct sequence) with rational counting (one number word is attached to each object; NCTM 2000). We see it as evidence of the strong value placed on locating learning within meaningful contexts, even if it violated the definition of a term. We wonder if it is a window on how counting in the classroom, particularly in the routine contexts, is not a single thing. The act of counting days on the calendar or number of children at school today is rote counting for some children and rational counting for others. The degree to which something is meaningful is set by the teacher and also by the child.

4. This contrast is an interesting one because CGI is seen to provide a meaningful context for learning operations. For four year olds, it was not seen as meaningful enough.

\section{References Cited}

de Abreu, Guida

1995 Understanding How Children Experience the Relationship between Home and School Mathematics. Mind, Culture, and Activity 2(2):119-142.

Baker, Dave, Brian Street, and Alison Tomlin

2003 Mathematics as Social: Understanding Relationships between Home and School Numeracy Practices. For the Learning of Mathematics 23(3):11-15.

Barnett, W. Steven, Megan Carolan, Jen Fitzgerald, and James Squires

2012 The State of Preschool 2012: State Preschool Yearbook. New Brunswick: National Institute for Early Education Research.

Blank, Jolyn

2010 Early Childhood Teacher Education: Historical Themes and Contemporary Issues. Journal of Early Childhood Teacher Education 31(4):391-405.

Bloch, Marianne

1987 Becoming Scientific and Professional: Critical Perspectives on the History of Early Childhood Education. In The Formation of School Subjects. Thomas Popkewitz, ed. Pp. 25-62. London: Falmer.

Boaler, Jo

1999 Participation, Knowledge and Beliefs: A Community Perspective on Mathematics Learning. Educational Studies in Mathematics 40:259-281.

Bredekamp, Sue

2009 Early Learning Standards and Developmentally Appropriate Practice: Contradictory or Compatible. In Continuing Issues in Early Childhood Education. Stephanie Feeney, Alice Galper, and Carol Seefeldt, eds. Pp. 258-271. New York: Merrill.

Brown, Christopher

2008 Keep It Cheap, Keep It Local, and Keep It Coming: Standards-Based Accountability Reform in Wisconsin. Educational Policy 22(2):250-294.

Camilli, Gregory, Sadako Vargas, Sharon Ryan, and W. Steven Barnett

2010 Meta-Analysis of the Effects of Early Education Interventions on Cognitive and Social Development. Teachers College Record 112(3):579-620. 
Carpenter, Thomas, Elizabeth Fennema, Megan Franke, Linda Levi, and Susan Empson 1999 Children's Mathematics: Cognitively Guided Instruction. Portsmouth: Heinemann.

Civil, Marta, and Leslie Khan

2001 Mathematics Instruction Developed from a Garden Theme. Teaching Children Mathematics 7(7):400-405.

Cohen, Jennifer

2010 Getting Recognised: Teachers Negotiating Professional Identities as Learners Through Talk. Teaching and Teacher Education 26(3):473-481.

Duncan, Greg, Chantelle Dowsett, Amy Claessens, Katherine Magnuson, Aletha Huston, Pamela

Klebanov, Linda Pagani, Leon Feinstein, Mimi Engel, Jeanne Brooks-Gunn, Holly Sexton, Kathryn

Duckworth, and Crista Japel

2007 School Readiness and Later Achievement. Developmental Psychology 43(6):1428-1446.

Eisenhauer, Mary Jane, and David Feikes

2009 Dolls, Blocks, and Puzzles: Playing with Mathematical Understanding. Young Children 64(3):18-24.

Gilliam, Walter, and Edward Zigler

2001 A Critical Meta-Analysis of All Evaluations of State-Funded Preschool from 1977 to 1998: Implications for Policy, Service Delivery and Program Evaluation. Early Childhood Research Quarterly 15(4):441-473.

Ginsburg, Herbert, P.

2006 Mathematical Play and Playful Mathematics: A Guide for Early Education. In Play=Learning: How Play Motivates and Enhances Children's Cognitive and Social-Emotional Growth. Dorothy Singer, Roberta Michnick Golinkoff, and Kathy Hirsch-Pasek, eds. Pp. 145-165. New York: Oxford University Press.

Goldstein, Lisa S.

2007 Beyond the DAP Versus Standards Dilemma: Examining the Unforgiving Complexity of Kindergarten Teaching in the United States. Early Childhood Research Quarterly 22(1):39-54.

Gonzalez, Norma, Louis Moll, and Cathy Amanti

2005 Funds of Knowledge: Theorizing Practices in Households, Communities, and Classrooms. Mahwah: Lawrence Erlbaum Associates, Inc.

Guernsey, Lisa, and Sara Mead

2010 A Next Social Contract for the Primary Years of Education. Washington, DC: New America Foundation.

Halpern, Robert

2013 Tying Early Childhood Education More Closely to Schooling: Promise, Perils and Practical Problems. Teachers College Record 115(1):1-28.

Hatch, J. Amos

2002 Accountability Shovedown: Resisting the Standards Movement in Early Childhood Education. Phi Delta Kappan 83:457-462.

2010 Rethinking the Relationship between Learning and Development: Teaching for Learning in Early Childhood Classrooms. The Educational Forum 74(3):258-268.

Hedges, Helen

2011 Rethinking Spongebob and Ninja Turtles: Popular Culture as Funds of Knowledge for Curriculum Co-Construction. Australasian Journal of Early Childhood 36(1):25-29.

Holland, Dorothy, William Lachicotte, Deborah Skinner, and Carole Cain

1998 Identity and Agency in Cultural Worlds. Cambridge, MA: Harvard University Press.

Katz, Lilian

1995 Talks with Teachers of Young Children: A Collection. Norwood: Ablex Publishing Corporation.

Klibanoff, Raquel, Levine, Susan, Huttenlocher, Janellen, Vasilyeva, Marina, and Larry Hedges

2006 Pre-School Children's Mathematical Knowledge: The Effect of Teacher "Math Talk." Developmental Psychology 42(1):56-69.

Lee, Joon Sun

2006 Preschool Teachers' Shared Beliefs about Appropriate Pedagogy for 4-Year-Olds. Early Childhood Education Journal 33(6):433-441.

Lee, Joon, and Herbert Ginsburg

2009 Early Childhood Teachers' Misconceptions about Mathematics Education for Young Children in the United States. Australian Journal of Early Childhood 34(4):37-45.

Matthews, Dylan

2013 Obama's PreK Plan. Washington Post, February 14. http://www.washingtonpost.com/ blogs/wonkblog/wp/2013/02/14/read-obamas-pre-k-plan/ 
Moll, Luis, Cathy Amati, Deborah Neff, and Norma Gonzalez

1992 Funds of Knowledge for Teaching: Using a Qualitative Approach to Connect Homes and Classrooms. Theory into Practice 31(2):132-141.

Moloney, Mary

2010 Professional Identity in Early Childhood Care and Education: Perspectives of Pre-school and Infant Teachers. Irish Educational Studies 29(2):167-187.

Nasir, Na'ilah, and Jamal Cooks

2009 Becoming a Hurdler?: How Learning Settings Afford Identities. Anthropology \& Education Quarterly 40(1):41-61.

National Council of Teachers of Mathematics

2000 Principles and Standards for School Mathematics. Reston: National Council of Teachers of Mathematics.

National Research Council

2009 Mathematics Learning in Early Childhood: Paths toward Excellence and Equity. Washington, DC: National Academy Press.

Romano, Elisa, Dafna Kohen, Lyzon Babchishin, and Linda Pagani

2010 School Readiness and Later Achievement: Replication and Extension Study Using a NationWide Canadian Survey. Developmental Psychology 46(5):995-1007.

Seo, Kyoung-Hye, and Herbert P. Ginsburg

2004 What Is Developmentally Appropriate in Early Childhood Mathematics Education?: Lessons from New Research. In Engaging Young Children in Mathematics: Standards for Early Childhood Mathematics Education. Douglas Clements and Julie Sarama, eds. Pp. 91-104. Mahwah: Lawrence Erlbaum Associates.

Sleeter, Christine

2001 Preparing Teachers for Culturally Diverse Schools: Research and the Overwhelming Presence of Whiteness. Journal of Teacher Education 52(2):94-106.

Stipek, Deborah, and Patricia Byler

1997 Early Childhood Education Teachers: Do They Practice What They Preach? Early Childhood Research Quarterly 12(3):305-325.

Thomas, Louise, Elizabeth Warren, and Eva deVries

2011 Play-Based Learning and Intentional Teaching in Early Childhood Contexts. Australian Journal of Early Childhood 36(4):69-75.

Tudge, Jonathan, and Fabienne Doucet

2004 Early Mathematical Experiences: Observing Young Black and White Children's Everyday Activities. Early Childhood Research Quarterly 19:21-39.

van Oers, Bert

2010 Emergent Mathematical Thinking in the Context of Play. Educational Studies in Mathematics 74(1):23-37.

Velez-Ibanez, Carlos, and James Greenberg

1992 Formation and Transformation of Funds of Knowledge. Anthropology and Education Quarterly 23(1):313-335.

Zembylas, Michalinos

2005 Discursive Practices, Genealogies, and Emotional Rules: A Poststructuralist View on Emotion and Identity in Teaching. Teaching and Teacher Education 21(8):935-948.

Zigler, Edward, Walter S. Gilliam, and W. Steven Barnett

2011 The Pre-K Debates: Current Controversies and Issues. Baltimore: Brookes Publishing. 